\title{
Communications
}

\section{Optic neuropathy of recurrent blood loss}

\section{A. CHISHOLM}

From the Tennent Institute of Ophthalmology, University of Glasgow, and the Glasgow Eye Infirmary

Loss of vision after severe and recurrent haemorrhage, an occasional but serious complication, is an established clinical entity recognized from the writings of the earliest medical authorities. Formerly thought only to follow recurrent upper gastrointestinal (Goerlitz, 1920; Bamford and Barber, I940; Black, I945; Avery Jones, I947; Locket, I949; Gavey, 1963), uterine (Pines, 1931), or therapeutic bleeding (Esquirol, 1838 ), it is now recognized that similar visual loss may follow open heart surgery (Lamb, I 96 I ; Gilman, 1964) and cardiac arrest (Weinberger, 1962). This paper presents three instances in which the visual loss followed closely on surgery and one in which the classical pattern evolved.

\section{Case reports}

Case I, a man aged 31 years, had chronic pulmonary tuberculosis with recent exacerbation treated by chemotherapy (Inahpasade $12 \mathrm{~g}$./day). His vision was said to be good before admission. The blood pressure on admission was $130 / 70 \mathrm{~mm}$. $\mathrm{Hg}$.

4.6.65 Upper right lobectomy.

14.6.65 Closure of broncho-pleural fistula.

1.7.65 Middle and lower right lobectomy and thoracoplasty for empyema and bronchial fistula. This was a long procedure complicated by brisk haemorrhage from the pulmonary vessels and a period of profound hypotension. An intravenous infusion, initially of blood and latterly of 5 per cent. dextrose/saline, was started at the time of operation and continued for 24 hours postoperatively; 5 pints of whole blood were transfused during the operation, and bronchoscopy and tracheostomy were performed later that day.

2.7.65 The patient complained of being unable to see, and examination showed that the visual acuity in the right eye was reduced to perception of light only, while the left eye had doubtful perception of light. The pupils were semi-dilated and only the right pupil showed any reaction to light. There was slight oedema of the optic discs and adjacent retina in each eye. The retinal vessel calibre was within normal limits. A diagnosis of neuroretinal oedema secondary to hypotension was made and therapy with osmotic agents instituted. Intravenous "Ureaphil", $40 \mathrm{~g}$. in $500 \mathrm{ml}$. saline was given and followed by intravenous "Mannitol". The "Mannitol" was administered as a Io per cent. solution in saline: $500 \mathrm{ml}$. of this solution was given over 6 hours and was alternated with $540 \mathrm{ml} .5$ per cent. dextrose saline for the next 4 days. A good diuresis was obtained and maintained. 
3.7.65 There was subjective improvement in visual acuity, but neither pupil reacted to light Neuroretinal oedema was still present. A homonymous field defect was revealed on confrontation testing. Weakness of the left arm and fingers was now apparent.

5.7.65 Only 2 days later the patient was able to distinguish moderately-sized print. Some $\stackrel{\vec{F}}{\stackrel{\vec{\rho}}{2}}$ oedema was still present at the margin of the optic discs.

9.7.65 The patient was able to read small print, and the visual field defect was much smaller on confrontation testing.

24.7.65 Before the patient's discharge from the ward the visual acuity with glasses was $6 / 5$ and N. 5 ॐ with each eye. An ophthalmoscopical examination revealed normal optic discs and $\bar{O}$ retinae. The visual fields were full.

Only slight weakness of finger movements of the left hand remained.

Case 2, a woman aged 57 years, was a cardiac cripple with mitral stenosis following rheumatic fever at the age of 13 years. She was considered to be a poor surgical risk and was inir cardiac failure for which she was having Cedilanid $0.15 \mathrm{mg}$. three times a day and Warfarin $7.5 \mathrm{mg}$. daily. Her sight was said to be good. The blood pressure on admissiono was $\mathrm{I} 35 / 8 \mathrm{omm}$. $\mathrm{Hg}$.

9.9.65 Mitral valvotomy. There was difficulty in resuscitation immediately postoperatively The blood pressure was very low, but improved with vasopressor agents and blood trans- fusion.

13.9.65 Small pneumothorax tapped.

16.9.65 The patient was found to be very drowsy.

19.9.65 She complained of blurred vision, and examination showed that the visual acuity in eachő eye was reduced to "counting fingers". Both pupils showed a sluggish reaction to light. $\stackrel{\mathbb{2}}{2}$ Low-grade oedema of the optic disc was present with scattered haemorrhages close to the $\overrightarrow{0}$ left optic disc. Both optic discs were rather pale and examination of the visual fields revealed a central scotoma in each eye. Therapy was instituted with prednisolone $15 \mathrm{mg}$, three times a day, reduced over the next 2 days to $5 \mathrm{mg}$. three times a day and continued: for Io days.

4.10.65 Visual acuity in both eyes improved to 6/18. Oedema of the optic discs was now absent. The central scotomata were now improved but the fields of vision were still constricted. There was also an acquired colour blindness.

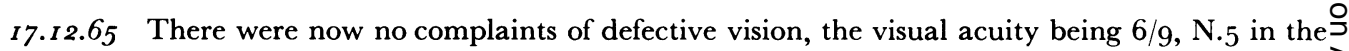
right eye and $6 / 6, N .5$ in the left. The optic discs remained pale but there was no oedema. The visual fields remained constricted, and there was a generalized depression of colour discrimination on testing with the Farnsworth-Munsell roo Hue test.

Case 3, a man aged 52 years, had had a febrile illness in October, 1960, which was followed by obstructive jaundice. The visual acuity in each eye was said to be good before admission to hospital. The blood pressure on admission was $130 / 90 \mathrm{~mm}$. $\mathrm{Hg}$.

25.1.6I Cholecystectomy and choledolithotomy. The immediate postoperative condition was satisfactory.

28. I.6I Severe haemorrhage from the wound led to shock, and the blood pressure went down to $88 / 55 \mathrm{~mm}$. Hg. He was transfused with 5 pints of whole blood. The wound was $\mathbb{\mathbb { D }}$ explored under general anaesthesia and a large quantity of blood and bile was aspirated from the peritoneal cavity. 
4.2.6I The wound ruptured; he was again shocked and the blood pressure fell to $90 \mathrm{~mm}$. $\mathrm{Hg}$ systolic; the diastolic blood pressure could not be recorded.

5.2.6I The wound was resutured under general anaesthesia. The patient was in a state of electrolyte imbalance for the next 2 weeks and required intravenous fluids.

23.2.6I The $\mathrm{Hb}$ was $57 \mathrm{~g}$. per cent. and he was transfused with 3 pints of whole blood.

I4.3.6I The patient's general state was improving, but he was complaining of poor vision, and an ophthalmological examination was carried out in the ward. There was bilateral optic atrophy, more marked in the left eye.

9.6.6 I The visual acuity was reduced to $\mathrm{I} / 8$ in the right eye with no perception of light in the left. The intraocular pressure was above normal and miotics were prescribed.

There has been no return of vision to the left eye, but the visual acuity in the right eye has improved to 6/12. The glaucoma in the right eye is controlled with pilocarpine drops 2 per cent. three times a day, though the field of vision is reduced.

Case 4, a man aged 64 years, came to the out-patients clinic in June, I966, with a complaint of poor vision in both eyes of 3 weeks' duration. Some 6 weeks previously he had had a massive epistaxis which lasted 2 hours and during which he estimated his blood loss as 2 pints, although he did not collapse.

He had experienced recurrent epistaxis, once or twice a year since 1934, but never before so profuse. He had had a right inguinal herniorrhaphy in January, I966, and haemorrhoidectomy for repeated rectal bleeding over the previous $2 \frac{1}{2}$ years. He also reported bleeding excessively after accidental wounding.

The blood pressure was recorded as $140 / 90 \mathrm{~mm}$. $\mathrm{Hg}$.

There was no family history of ocular disease. The visual acuity was $6 / 12$ in the right eye and counting fingers in the left. Fundus examination revealed oedema and pallor of the optic discs and scattered haemorrhages adjacent to the right disc.

28.6.66 He was admitted to hospital for investigation of low-grade papilloedema. The haemoglobin was i I g. per cent. and the packed cell volume 36 per cent. The blood pressure was $170 / 100 \mathrm{~mm}$. $\mathrm{Hg}$. A full medical and radiological examination failed to reveal any intracranial cause for the ocular signs.

30.3.67 There was marked pallor of the optic disc, right less than left. The visual fields showed an altitudinal scotoma before each eye. The visual acuity was unchanged. Examination of the colour discrimination of the better (right) eye showed a yellow-blue defect. The intraocular pressure and the facility of outflow of aqueous humour in each eye was well within normal limits.

\section{Discussion}

The visual loss following haemorrhage is usually bilateral although the eyes may be unequally affected. The amaurosis usually appears either within the first 24 to 48 hours, or Io to 20 days after the antecedent event (Fries, 1876). Ulrich (1887) described a retinopathy of haemorrhages and exudates in several patients after recurrent severe upper gastrointestinal haemorrhage. Pagenstecher (1905) attributed this retinopathy to anaemia; his observations showed that the retinopathy developed to to 20 days after the haemorrhage and closely resembled the retinal appearances found in chlorosis. It is established that amaurosis never follows a single haemorrhage from a person in normal health (Locket, I 949) and this is given as the reason for the rarity of amaurosis following war wounds during the periods I914-1918 and I939-1945. 
Gowers (I 882) appreciated that damage to the nutrition of the retina might lead to thक्ष appearance of a "primary inflammation" on restoration of the blood supply and thu疋 account for the ophthalmoscopic signs.

The pathological examination of eyes by Ziegler (1887), Goerlitz (1920), and Ashton Pears, and Pickering ( $196 \mathrm{I}$ ) disproved the early theory that a retrobulbar haemorrhage was the underlying cause of the amaurosis. Ziegler (1887) was the first to attribute the्ष retinal changes to ischaemia. This theory was enlarged upon by Pears and Pickerin ( 1960), who on a clinical basis ascribed the changes in the retina and optic nerve head t@i anoxia secondary to a profound fall in blood pressure. Such a condition would be inten= sified by a pre-existing anaemia. They described the ophthalmoscopic signs as a neuro retinopathy with oedema of the retina and optic nerve head, scattered retinal haemorrhag $\overrightarrow{\omega_{\sigma}}$ adjacent to the optic discs, and occasional "cotton-wool" exudates. They also pointed out the similarity between this retinopathy and that found in fulminating hypertension: sub-acute bacterial endocarditis, and the collagen group of diseases, although of course्ध the other signs were lacking. Pears and Pickering ( 1960 ) discounted the idea that a raised cerebrospinal fluid pressure was the cause of the neuroretinal oedema, and felt that it waş due to an abnormal permeability of the capillaries in response to local tissue anoxia. Thi would be an immediate result of the hypotensive circulatory changes consequent of haemorrhage, or a delayed result of anaemia.

That the neuroretinal oedema and the "cotton-wool" spots are the result of a focal break $\overrightarrow{0}$ down in the blood-retinal barrier has been confirmed by the work of Ashton ( 1965 ).

A minority of cases of the immediate type in the past have recovered vision to some degree, but have generally shown residual scotomata in one or both eyes (Fries, 1876 ) The field defects are frequently altitudinal and are said to be the result of anoxic damage to the retina, the upper retina being preferentially affected because of the influence oळ gravity.

Case I was seen in the initial phase of a dramatic onset of almost total blindness. The oedema was confined to the optic disc margin and the adjacent retina in each eye. This was thought to be due either to hypotension at the time of operation or to an aeroembolus? The clinical impression favouring hypotension, an osmotic diuresis was instituted. The. full return of both visual function and of motor function to the affected left arm was gratifying. It is not known, of course, if this patient would have recovered spontaneously or what part, if any, the disturbance of the blood gases produced by an open broncho@ pleural fistula played in the production of the amaurosis.

Case 2 belongs to the group in which failure of vision is delayed and in which the prognosis in the past was more hopeful; Fig. I shows the area adjacent to the left optic dis at the initial ophthalmic examination. The central visual field defects cleared and the visual acuity returned to a satisfactory level, an improvement which has been maintained?

Case 3 in retrospect has been complicated by a pre-existing unrecognized chronic simple glaucoma. Perez Llorca ( 1963 ) stressed that an eye affected by chronic glaucoma deter iorated quickly in patients with a low blood pressure and that a rapid deterioration if vision could be expected in glaucomatous eyes if there was a profound fall in the bloofే pressure. Givner and Jaffe (1950) drew attention to several instances in which centraf retinal artery occlusion followed anaesthesia during which there has been haemorrhagi hypotension, plus accidental external pressure on the eyeball.

Case 4 was seen when the secondary stage of optic nerve atrophy was already establishe and it is questionable if any therapy could have had a beneficial effect. Fig. 2 shows the appearance of the right optic disc. The history shows that this patient belongs to th气ิ 


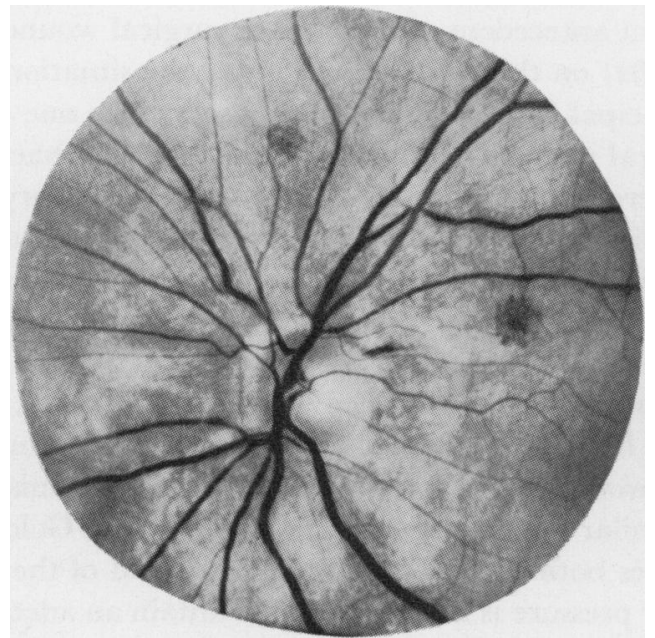

FIG. I Ciase 2. Fundus photograph of left eye, showing area of optic disc

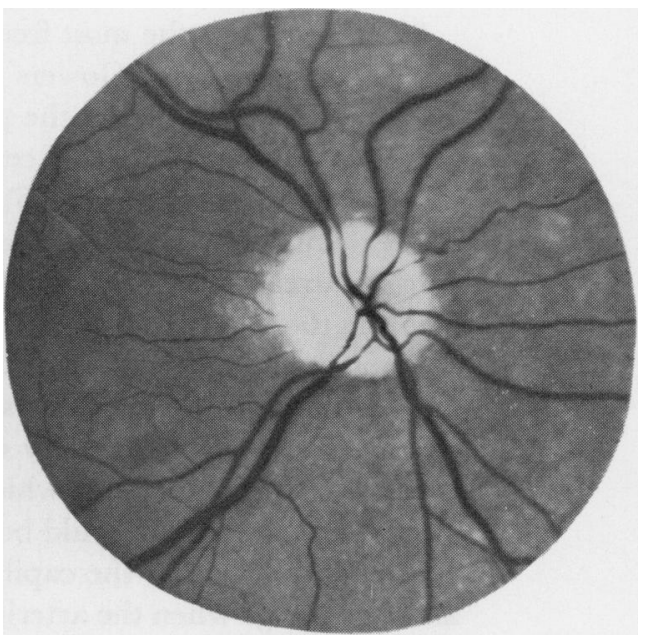

FIG. 2 Case 4. Fundus photograph of right eye, showing degree of optic atrophy

delayed group. The long history of rectal bleedings, ending with the haemorrhoidectomy in January, I966, doubtless played a part. Glaucoma as a contributory factor was eliminated on investigation. The patient shows an altitudinal scotoma present in the field of vision of each eye (Fig. 3) and the presence of retinal change is confirmed by the acquired yellow-blue (tritanopic) defect in colour vision as detected by the Farnsworth Munsell r oo Hue test (Fig. 4).
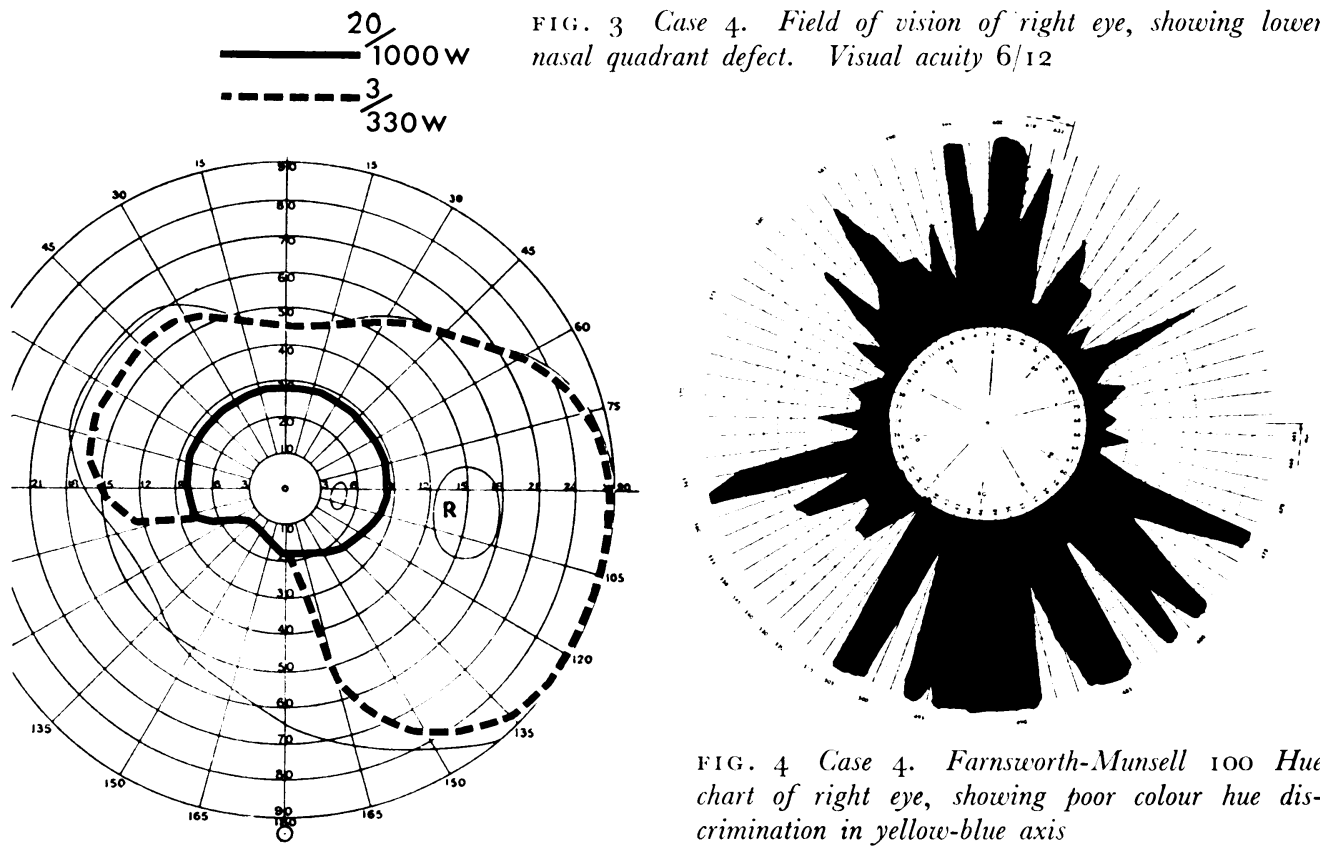

FIG. 4 Case 4. Farnsworth-Munsell ioo Hue chart of right eye, showing poor colour hue discrimination in yellow-blue axis 
"Venesection is the most frequent antecedent, accidental or surgical wounds being ver rare causes", so wrote Gowers (I882) on this problem. To-day the situation has altered Anoxaemia is accepted as the principal factor in the visual upset. It is one of the factors discussed in the causation of cerebral infarction following gastrointestinal haemorrhage byas Hannah and Goldberg (1966), cerebral disorders following cardiac surgery by Gilmarg ( I 964), ocular changes during cardiac surgery by Lamb ( I96i ), and cortical blindness afte홍 cardiac arrest by Weinberger (1962). Anoxaemia was considered the major aetiologica factor in the neonate found to have optic atrophy following a massive maternal antepartuma haemorrhage (Carreras, 1954).

It is doubtful if the ocular signs are visible evidence of more widespread neurologica $\vec{P}$ damage from which recovery can be made. Case I had the additional complication of weakness of the left hand which would indicate a lesion of the right hemisphere. Tho causation of this lesion could be similar to that described by Hannah and Goldberg (1966) It would appear that the capillaries both of the optic nerve head and of the retina suffef anoxic damage when the arteriolar pressure is insufficient to maintain an adequate circula or tion. The reason why the optic nerve head is singled out is the tissue pressure to which the area is subjected. The terminal branches of the vascular supply pass from an extraocular area of low to an intraocular area of high tissue pressure. Should the arterial pressure be insufficient to overcome this pressure gradient, ischaemia results.

Primrose (1964), in a discussion of the anatomical criteria of papilloedema and optic atrophy, showed how the intraluminal pressure of the capillaries in the optic nerve head was dependent on the intraocular pressure, the blood pressure, and the intracraniab pressure. Ischaemia of the optic nerve head could arise as a result of raised intraocular pressure, as in glaucoma, or of a lowered arterial pressure; in combination their individuab effects would be enhanced. The anatomical variations in the arterial supply as well as th: oxygen-carrying capacity of the blood, the degree of sclerosis, and the presence or absence of inflammatory change in the vessel wall, play a part in the production of ischaemię changes. There is as yet insufficient knowledge of the unique anatomical arrangements and physiological requirements of these small vessels.

\section{Summary}

Four cases of visual disturbance after haemorrhagic hypotension are described. Formerl $\frac{3}{5}$ such visual disturbance produced permanent visual defects varying from total blindness tỏ small scotomata. Details are given of a successfully treated case. Various aetiologicab factors are discussed. An attempt is made to draw attention to the diversity of the causa tion of the condition.

My thanks are due to Prof. W. S. Foulds, Prof. A. W. Kay, and Mr. K. Fraser, of the Western Infirmary, and to Dr. W. Wilson of the Ophthalmic Institution for permission to publish details of cases under their care and to Mr. John Watt and Mrs. A. Currie for the excellence of the retinal photographs.

\section{References}

Ashton, N. (1965) Trans. ophthal. Soc. U.K., 85, 199

-, PeArs, м. A., and Pickering, G. w. (196i) Brit. J. Ophthal., 45, 385

BAMFORD, C. H., and BARBER, H. (I940) Lancet, 2, I 75

BLACK, J. (1945) Brit. med. J., 2, 920

CARreras, m. (I954) Arch. Soc. oftal. hisp.-amer., r4, 405

ESQUirol, E. (1838) “Des maladies mentales", vol. I, p. I83. Baillière, Paris 
FRIES, s. (1876) Klin. Mbl. Augenheilk., 14, pt. 3, p. 3 GAVEY, c. J. (1963) Trans. ophthal. Soc. U.K., 83, 315

gilman, s. (1964) New. Engl. J. Med., 272, 489

GIVNER, I., and JAFFe, N. (1950) Arch. Ophthal. (Chicago), 43, 197

GoerLitz, M. (1920) Klin. Mbl. Augenheilk., 64, 763

Gowers, w. R. (1882) “A Manual and Atlas of Medical Ophthalmoscopy”, 2nd ed. Churchill,

London

HANNAH, R., and GOLDBERG, A. (1966) Scot. med. F., II, I53

JONES, F. AVERY (1947) Brit. med. J., 2, 477

LAMB, A. (196I) Brit. F. Ophthal., 45, 490

LOCKET, S. (1949) Ibid., 33, 543

Pagenstecher, A. H. (1905) Arch. Augenheilk., 52, 237

PEARs, M. A., and PICKering, G. w. (I96o) Quart. J. Med., 29, I 53

PEREZ LlORCA, J. (1963) Arch. Soc. oftal. hisp.-amer., 23, 966

PINES, N. (1931) Brit. F. Ophthal., 15, 75

PRIMROSE, J. (1964) Ibid., 48, I9

ULRICH, R. (1887) v. Graefes Arch. Ophthal., 33, (pt. I), p. I

Weinberger, H. A. (1962) J. Amer. med. Ass., 179, 126

ziegler, E. (1887) Beitr. Path. Anat. Physiol., 2, 57 